\title{
Towards a spatially and socially embedded approach to SME support for carbon reduction
}

\author{
Will Eadson* \\ Sheffield Hallam University
}

\begin{abstract}
This paper discusses support for Small and Medium Enterprises (SME) to encourage carbon reduction in relation to conceptualisations of SMEs as socially and spatially embedded entities. The conceptual discussion is married to conclusions from an evidence review of SME carbon reduction support to argue that there is a need for coordinated local support architecture framed around both recognising and fostering the notion of SMEs as 'spatially tied' local citizens. The paper concludes with a discussion of the practical policy implications of such an approach, including wider projects of civic engagement with SMEs alongside focused, targeted interventions aimed at disruptive change to SME practices.
\end{abstract}

Keywords: Small firms, Small and Medium Enterprises, SME policy, carbon reduction.

\section{Introduction}

In this paper I consider contemporary research, policy and practice on carbon reduction in Small and Medium Enterprises ${ }^{1}$ (SMEs). In doing so I present some initial thoughts arguing for greater emphasis on Small and Medium Enterprises as socially and spatially embedded entities.

SMEs account for around 45 per cent of total business energy use (Vickers et al, 2009) and as a result represent an important target group for carbon reduction policy. Furthermore, there are seen to be significant inefficiencies in SME energy use, with Carbon Trust identifying close to a third of all SME energy use as 'waste' (ibid). The challenge for those seeking to address issues within the SME population is that SMEs as a whole tend to have low levels of engagement with support providers. Research for the Department of Business Innovation and Skills (BIS) shows that only 40 per cent of SMEs utilised some form of external assistance (not specific to any aspect of their business) and just 20 per cent utilised public sector support. This is likely to be lower still among micro and small firms (under 50 employees).

The UK has experienced over a decade of SME support focused on reducing carbon emissions, with an even longer history of support for 'sustainability' and environmental improvements through EU programmes. Yet there has been little consideration of 'what 
works', particularly when considering programmes specifically aimed at carbon reduction. Policy learning has been further hampered by the small-scale, fragmented nature of support programmes: there is no national coordinated programme of support for SMEs on carbon reduction. Indeed, the demise of Business Link means that there exists no coordinated system of business support at all in England.

Despite this, we know that most SMEs have taken some level of action on resource efficiency, but that this action is largely low-level and piecemeal (Federation for Small Business, 2008; Netregs, 2009). And significant barriers and market failures remain, most notably: lack of knowledge (imperfect information) about what SMEs might be able to do, including a perception that they have already implemented all sensible measures; lack of resources to implement change; perception that environmental improvements are costly; and lack of engagement with policy and external agencies. There are therefore two key policy challenges: to more effectively engage SMEs in carbon reduction support and policy; and to encourage disruptive change in SME energy practices.

This paper reflects on an evidence review carried out as part of a Higher Education Innovation Fund (HEIF) project to determine 'what works' in sub-national interventions on SME carbon reduction (Eadson, 2011). It drew on the Office of Project Advice and Training (OffPAT) database of Regional Development Agency evaluation and evidence reports, supplemented by a review of other 'grey' and academic literature. The review found that the evidence on how to encourage action on carbon reduction in SMEs is patchy, and largely lacks theoretical or conceptual depth. Evaluative evidence rarely quantified the impacts of carbon reduction support programmes, especially when considering net outcomes, and evaluation timescales meant that long-term impacts were not investigated. Further to this, there was a tendency towards an agent-focused approach to SME behaviour. In this paper I argue that this approach to understanding SME action on carbon reduction - and to policy development - works against the two challenges outlined above. I point to ways in which this might be alternatively approached at the regime (local economy, government and networks) and micro (individual firms) levels.

This is manifest in two interlinked discussions: first I consider the ways in which SMEs are geographically rooted; that is, embedded within the local areas that they inhabit, with resultant implications for consideration of civil society and local communities; and second, I consider SMEs as socio-technical entities in which actions are practice-based, that is, habitually undertaken activities held together by a variety of material, discursive and social elements. The practical implications of this are not necessarily radical, but do represent a shift in the current approach taken to business support more generally. In particular, they highlight the importance of local authorities and LEPs (with partners) in 're-filling' the local business support landscape following the coalition government's aggressive pruning of Business Link. It is important, however, to foreground this discussion with a brief consideration of the SME 'sector'.

\section{There is no SME sector}

A complicating factor to any consideration of SME support - as Blackburn and others continue to emphasise (see Blackburn, 2012) - the SME 'sector' is characterised above all else by heterogeneity. The term 'SME' covers a large size range, both in turnover and employee numbers. It also covers firms operating in all sectors of the UK economy, and smaller firms are more likely to operate according to the values of their owner: 
'Small firm' is not a description: it denotes membership of a sector which is a political and economic construct, relatively recent and still evolving. It is hard to see unifying characteristics. Many self-employed people would not think of themselves as small firms; and other businesses will define themselves sectorally ("I'm a butcher",) or by reference to their locality or region ("I run a northwest building firm'). They have different motivations: ('I'm an engineer - not an entrepreneur: I want to make things, not money')' (DTI, 2002: p. 14 cited in Blackburn, 2012).

The majority of research and evaluation with regard to resource efficiency and carbon reduction in SMEs has focused on the whole corpus of SMEs with little or no distinctions made for size or sector. This reflects the policies and programmes under consideration as much as the researcher gaze. It is important therefore to at least note that SME carbon reduction support needs to take a flexible approach allowing for the "unique nature" of SMEs (Crocker, 2012: 232). This has been an enduring critique of mainstream business support (see for example Curran and Blackburn, 2002).

\section{Geographically embedding SMEs and SME policy}

Highlighting the heterogeneous nature of SMEs and their owner-managers' differing self-identities is important in that it points to the necessity of viewing SMEs as subject to a wide range of socio-spatial ties: 'I run a northwest building firm'; becoming selfemployed in order to balance economic demands with family life (Dawson et al., 2012); a professional within a community of practice (Warren, 2004). Furthermore, there is evidence to suggest that the identity and/or values of SME owners are strongly tied to SME decision-making, particularly among smaller firms (Revell and Rutherford, 2003; Levitt, 2013). In addition, operating in the main as limited companies (when incorporated at all), these firms are not subject to wider financial market pressures nor a broad base of shareholders as in the case of public limited companies These businesses are not so much 'corporate citizens' with their own bureaucratic identities as direct extensions of the identities of business owner/owner-managers. This leads to three logical - if hardly groundbreaking - conclusions: (1) SMEs are not 'rational' actors seeking to maximise profits, led by a 'pure' and 'logical' decision-making calculus (at least, not in a classical economic sense); (2) as a result they are open to making decisions based on a range of value forms beyond monetary exchange value (manifest as profit) and beyond that captured by a limited economic notion of 'satisficing' tradeoffs; and (3) returning to the point at the start of this paragraph, they should be understood as socially and spatially embedded constructs.

While there is an array of literature regarding entrepreneurs as socialised actors, (see McKeever et al., 2014, for an overview) the nature of the spatial element of embedding is somewhat disputed, particularly the confluence of locality with SME networks. Although SMEs are often reliant on locality, and are often assumed to be more 'local' than large firms simply as a function of their size, SME attitudes differ. This is partly to do with a predominant feeling that, as an SME, their impact on local communities - either positive or negative - is negligible (Farinelli et al., 2005). Relatedly, Curran and Blackburn (1994) show that SME networks are often geographically stretched and - especially in the case of small and micro firms - often have very few employment ties to the local community. Curran (1993 p.10, cited in Blackburn, 2012) neatly summarises these points:

The assumption that locality coincides with the activities and 'world' of small business owners is misconceived since the market interactions of many SMEs 
p. 132. Towards a spatially and socially embedded approach to SME support for carbon reduction

reach beyond their immediate locality and owner-managers often have little affinity with the location in which their business is located.

Although now a decade old, NatWest/SERTeam (2004) provide some illuminating figures in this regard. Their survey of small businesses found that just a quarter of SMEs feel 'very much' part of their local community, although a further 30 per cent reported feeling part of their local community 'to an extent'. This chimes with a broader sense of SMEs as in some way 'insignificant' in their impacts: Farinelli et al (2005) also find that SMEs tend to assume that their environmental impact is negligible, and as such not worthy of attention.

Yet, others contend that, 'there remains some link between community and ownermanager' (Spence et al., 2003); and social relations of SMEs and/or their owners do hold significant power over their ethical behaviour (Fuller and Lewis, 2002). This inevitably contains a spatial dimension, even if only in the basic sense that all social relations are inherently spatial (Lefebvre, 1974). There is no a priori link between scale and ethical decision-making. That is, there is no necessary link between being embedded in local networks (of different forms) and action on carbon reduction. There is a long history of debate within the field of human geography regarding the continuing utility of notions of scale and in particular regarding the local (see Jonas, 2006) and it is important to avoid the 'local trap' or reifying the local as an arena for action (Born and Purcell, 2006). However, at the local level a range of factors can potentially be harnessed and brought together to generate engagement on this issue. These include: the material environment; day-to-day contacts; engagement with local 'anchor institutions', including local authorities; and potential for engagement in policy formation. For some firms this also extends to supply chains and customer base. In other words, the local is where social relations or networks are often materialised. Equally there is potential to strengthen these ties as a means to effecting change, as captured by the now relatively unfashionable notion of 'institutional thickness' (Amin and Thrift, 1995).

\section{Achieving disruptive change in SME practices}

While the above sections outline a more institutional perspective on SMEs, the following points relate to means of understanding decision-making and actions in SMEs at the micro level. This relates to the second of the challenges outlined above: how to effect disruptive change in SME energy practices. Much of the extant literature on carbon reduction in SMEs focuses is relatively low on theoretical insight as to what drives decision-making and actions in SMEs. While this literature often makes useful practical and policy recommendations (see for example, Bradford and Fraser, 2008) it does not tend to delve more deeply into sociological understandings of change. The body of work in this area might be categorised within what Elizabeth Shove (2009) terms the 'ABC' (attitudes, behaviour, choice) approach to action, based on a fairly uncritical (often implicit) application of basic classical and/or behavioural economics. An increasingly dominant approach in sustainability studies is the use of social practice theories to understanding habitual actions. Theories of practice, broadly defined, seek to understand both stability and change in how people act. The term covers a diverse set of approaches sharing a common thread: going beyond the classical problem of structure and agency by shifting focus 'from individual agents, their behavioural orientations and the constraints they face, to the emergence, development and disappearance of social practices' (Foden, 2015 forthcoming). Further to this, a key difference between contemporary approaches to social practices and earlier variants 
as espoused by, for example, Pierre Bourdieu (1990) or Anthony Giddens (1984) is the emphasis on the centrality of materiality within social practices.

Approaches adopting the principles of alternative conceptualisations of social practices are evident in research on entrepreneurship and SMEs (see for example, Higgins and Mirza, 2013; Vaara and Whittington, 2012) but literature searches provided only one example of the more recent conceptualisations of Elizabeth Shove and colleagues (see Hargreaves, 2011). The utility of this approach is that it 'decentres' the individual and focus on the interactions between the different material, discursive and social elements that come together in order for actions to take place. An enduring theme of this literature is the obduracy of many unsustainable practices due to the strength of the ties holding the elements together and reinforced by each performance of a practice. In a practical sense, the key to policy is about how to effect changes that sufficiently disrupt established practices so as to ensure lasting change.

One potential weakness of the practice approach relates to its consideration of value/s. Proponents of this approach highlight its usefulness in displacing simplistic approaches to understanding behaviour as being driven by individuals' attitudes and values. However, this runs the risk of losing notions of value in decision-making entirely. This stems from a suspicion of behavioural economic approaches to action, but there is potential for alternative, sociological accounts of activity that consider a more pluralistic understanding of value (see for example, Graeber, 2001) and its relevance to sociological research; and in this instance, SME behaviour. In other words, SMEs negotiate not only financial considerations but also other dimensions of value such as ethical considerations, possible 'brand' implications, and the 'use' or practicality of taking-up a particular practice or artefact, and the worth of following a particular course of action. These matters should be considered in thinking about changing SME practices. The reason for raising this here is that policy and practice should not lose all emphasis on values as drivers for action. This might provide a fruitful avenue for further research on SMEs and carbon reduction.

\section{Policy implications}

The first claim in this paper, that SMEs are a spatially embedded and that 'the local' can be an important part of this has a number of potential policy implications. From a pragmatic perspective, in the UK it is local organisations - LEPs and local authorities that have been charged with the development of business support following the demise of Business Link and also with catalysing the transition to a low carbon economy. Many of these organisations are using various European and UK government funding pots to begin this process. But if the local can have an advantage as the point at which policy, materiality and action 'come to ground' for SMEs then there is a case for not only local organisations acting on SME support for carbon reduction, but also for this support to include a focus on developing and reinforcing local ties as a means of achieving social and environmental goals. This is challenging in the context of existing SME support provision. Until 2011, Regional Development Agencies were the main conduit of SME support programmes at local and regional level, including coordination of regional Business Link networks. Local authorities and LEPs (by dint of their parvenu) do not have a history of dedicated SME support provision and to some extent the link between SMEs and the local institutional core is somewhat underdeveloped. The loss of local and regional advisors through Business Link heightens this 'local gap'.

Revell and Rutherfoord (2003: 26) argue that a 'lack of institutional enfranchisement for SMEs in the UK is a key factor in understanding why environmental policies have yet to be successful in encouraging more environmentally 
proactive behaviour within this sector'. Although they were concerned with national policy, this has clear relevance for local institutions, particularly where LEPs and local authorities can also draw together local Chambers of Commerce and branches of the Federation for Small Business, alongside other key 'anchor institutions'. The Camden Climate Change Alliance is one example where the use of large local private and public organisations to effectively 'brand' the initiative and create supply chain incentives has worked well to engage small firms on carbon reduction.

The second key claim of the paper is that at the micro level an emphasis on the (spatially embedded) social practices of SMEs would enable a better approach to indepth or disruptive change on carbon reduction. One implication of this is the need to emphasise focused and in-depth support rather than 'broad and shallow'. This tallies with Kevin Mole and colleagues' (2009) analysis of the Business Link local service:

...choice of intervention strategy has a significant effect both on actual and on perceived business outcomes, with our results emphasising the value of depth over breadth. The implication is that where additional resources are available for business support these should be used to deepen the assistance provided rather than extend assistance to a wider group of firms.

This is in contradistinction to the majority of projects reviewed for the evidence synthesis, where support was largely aimed at reducing emissions through resource efficiency of in-house processes. This focused on low-cost measures to reduce emissions through changes to practices relating to the 'low-hanging fruit', rather than large-scale, long-term transformations of behaviour. No projects involved introducing or developing new technologies to improve the efficiency of processes, or changing modes of energy supply within firms and there was little emphasis on businesses 'greening' supply chains, nor changing accounting practices to incorporate emissions (preferably including embedded emissions of consumed goods and services).

Material infrastructure (buildings, energy supply and so on) is an important factor, which returns to the points on spatial embeddedness above. But this needs also to be applied at the micro level. The difficulty in this case is ensuring that support is provided at the right critical juncture within a firm's life cycle: that is, when a firm might be looking to make changes to their premises or transport fleet regardless of carbon impacts. If material changes are important, which they undoubtedly are, then a serious challenge is raised - untouched within the literature to date - regarding the role of SMEs' landlords as a potential barrier (or possible driver), for action. Research in the domestic sphere suggests this could be a significant concern (see CRESR, 2012): there is a clear need for similar research for non-domestic stock. A third implication is the need to follow-up from original interventions: long-term disruption of existing practices and embedding new practices is a long-term process (if you'll excuse the tautology).

The conceptual discussion above also referred to the need to retain a notion of the 'agent-intermediary' through consideration of the ways in which SME practitioners might consider a range of different forms of value in making decisions about their business. This has a number of implications, but at the most basic level it means working to increase the value of carbon to SMEs in different ways. The evidence points to the fact that business are most likely to engage with policy interventions when owner-managers have an 'environmental conscience'. This suggests that there is a need to foster environmental values in SMEs, as a moral imperative. One suggested route to this is to link carbon reduction with localisation agendas which might play well with smaller SMEs in particular (and see discussion above). This might include focus on local trading networks, or engaging with arguments regarding the local multiplier effect 
and the role of localisation of energy and other key material resources in retaining wealth within local areas.

Interventions should also look to promote means of valuing carbon monetarily both within policy and firms. Vickers et al. (2009), discuss the need for carbon emissions to be made visible in SME decision-making processes. This might involve developing carbon accounting schemes; carbon valuations; whole-life costing of products and services; or more prosaic approaches such as the use of energy display monitors and smart meters. However, the take up of such approaches is likely to be similar to more general 'carbon audits' (that is, low) without a more conducive regulatory or market environment. Some cities and regions in Europe and the North America have trialled local emissions trading schemes. Although these have the same drawbacks as other voluntary initiatives, they can prove a way of engaging with environmentally-aware SMEs and also of raising the profile of low carbon transition agendas. This might also include ensuring that carbon is valued in SME or enterprise policy decision-making.

Finally, drawing the two key claims of this paper together, a small scale intensive area-based approach to carbon reduction at a local level has a number of advantages. This includes the possibility for bringing together a range of programmes in one place providing intensive support towards disruptive change within businesses (economies of scale); dealing with the external environment both brings business benefits (Defra, 2013) and also promotes environmental action more broadly; and the effect of bringing together a critical mass of businesses that can share experiences and also create a culture of action may in turn lead to policy-avoidance firms outlined by Parker et al (2007) becoming more engaged. These themes are also reflected in work on areabased initiatives for domestic retrofit and modernisation (see for example DECC, 2011). However, there remains a gap in the literature in understanding how policy can help groups of firms work together on carbon reduction. An example of such an approach is the Green Business Parks initiative in the North West. This project, delivered by Groundwork, involved the development of a suite of support services to businesses and involved wider environmental improvements within the targeted business parks. This project provides a good example to underscore key points made above.

First, the project worked well to engage with different public and private sector networks in the process of developing and implementing interventions to generate effective 'buy-in' from different partners as well as create a strong image for prospective beneficiaries. This included continual engagement with partners and SMEs regarding the successes and challenges of the project as it was implemented. Second, because the project was targeted at small geographic areas, face-to-face contact was less costly to implement than might otherwise be the case. As a result, the project team were able to develop more in-depth relationships and foster trust with those businesses that do not typically engage with business support or the public sector more generally. This helped to also create a more demand-led approach to the business (Enviros, 2007). Given the geographic focus, a drawback to this approach is that its reach might be limited if not part of a wider programme of support. Here, the key might be to ensure that broader methods of SME engagement across local areas are used to promote such projects as 'beacons' from which other SMEs can learn (as often attempted with area-based domestic retrofit projects).

\section{Conclusions}

Curran (2000) questions the need for SME business support in the context of high enterprise growth. The argument about support for businesses to start-up, survive and grow is slightly different to the case for support on resource efficiency, however. This is 
more clearly a moral-ethical concern, albeit with possible potential for material gains for individual businesses. This creates some differing challenges for business support providers compared to more mainstream support.

The fact that there is little evidence on the effectiveness of SME interventions on carbon reduction creates a challenge in itself and this is an issue that needs further work to address. However, drawing on what evidence does exist relating to SME policy and practice on carbon reduction this paper argued for increased consideration of SMEs as socio-spatial entities, in line with the broader literatures on enterprise and on sustainability. Understanding the spatiality of SME networks and how policy can best make use of, strengthen or adapt these connections also remains an area for further research.

There is a long and tortuous history of debate regarding the continuing utility of concepts such as 'the local', and in particular regarding the value of considering sociospatial relations in this way. There is no denying that action at the local level is inevitably bound and shaped by supra-local influences. And in an arena such as carbon reduction much of the work to engender a shift to a low carbon economy will take place at the national and supra-national levels of government; and much of the change that takes place will involve networks that reach beyond clear teritorial definitions. Fiscal policy, large-scale infrastructure investments and regulation are more likely to be dealt with by national and supra-national organisations and local level action will seek to either inform or supplement these actions. However, the local remains an important sphere for governing low carbon transitions, including within SMEs.

There is need for further work to more effectively untangle the civic or socio-spatial relations of SMEs and how this can be used to develop more effective policy, but the discussion here leads to three conclusions: (1) SMEs are - to varying degrees - bound to localities through social ties; but, (2) there is potential for SMEs to be more embedded within local civic networks; and (3) this could lead to stronger engagement with SMEs on carbon reduction and possibly other policy areas that might loosely be considered under the umbrella of sustainability. If SMEs were more effectively tied into policy formation, and their engagement with communities and the physical environment recognised and cultivated in local policy formation, interventions might be both more effective and reach a greater number of firms.

Taking this discussion as a starting point, the two linked challenges outlined above - engagement and action - point in slightly different directions for practice. Engendering disruptive change in SME practices requires specific and intensive support. Low-level action is already taking place, and a broader programme of SMEcivic engagement which would offer a route to inculcating this further. The use of mainstream services to do the latter would seem to make sense, which can then act as a gateway to more intensive support for those that seek it. The broader engagement work should be low-cost and focus on strengthening existing ties through engagement with networks and information provision (for example through online portals). As Rob Bennett (2008) argues, resources should be spent where they have most impact, and that is through targeted, in-depth work. In doing so it might be possible to draw the two sets of issues together in practice: the case of the Green Business Parks above provides one example of how this might be achieved.

One issue not tackled in this paper is that of firms who actively avoid action, even where mandatory standards are in place. This is a particularly difficult area to cover for local agencies given the lack of general resources to divert towards enforcement. While a stronger 'civic core' in which SMEs are collectively active might help to create an environment whereby such action is less easily taken, this remains an area within 
p. 137. Towards a spatially and socially embedded approach to SME support for carbon reduction

which strong and equitable regulatory and fiscal intervention is required: something that local authorities will struggle to achieve in the current fiscal climate.

\section{Notes}

1 Private sector firms with fewer than 250 employees.

* Correspondence Address: Will Eadson, Centre for Regional Economic and Social Research, Sheffield Hallam University, City Campus, Howard Street, Sheffield S1 1WB. Email: w.eadson@shu.ac.uk

\section{References}

Amin, A. and Thrift, N. (1995) Globalisation, institutional 'thickness' and the local economy". In: Healey, P., Cameron, S., Davoudi, S., Graham, S. (eds) Managing Cities: The New Urban Context. London: John Wiley and Sons.

Bennett, R. (2008) SME policy support in Britain since the 1990s: what have we learnt? Environment and Planning C, 26, 375-397.

BIS (2011) Small Business Survey 2010. London: HMSO.

Blackburn, R. (2012) Segmenting the SME Market and Implications for Service Provision: A Literature Review. London: Acas. http://www.acas.org.uk/media/pdf/0/5/0912-Segmenting_the_SME_market_Literature review.pdf

Born, B. and Purcell, M. (2006) Avoiding the Local Trap Scale and Food Systems in Planning Research. Journal of Planning Education and Research, 26, 2, 195-207.

Bourdieu, P. (1990) The Logic of Practice. Cambridge: Polity Press.

Bradford, J. and Fraser, E.D.G. (2008) Local Authorities, Climate Change and Small and Medium Enterprises: Identifying Effective Policy Instruments to Reduce Energy Use and Carbon Emissions. Corporate Social Responsibility and Environmental Management, 15, 156-172.

CRESR (2013) Attitudes and Perceptions of the Green Deal amongst private sector landlords in Rotherham. Sheffield: Sheffield Hallam University. http://www.shu.ac.uk/research/cresr/sites/shu.ac.uk/files/green-deal-landlordsrotherham.pdf

Crocker, R. (2012) SME Perceptions of Low Carbon Options: Drivers, Barriers and Business Sector Differences. Earth and the Environment, 7, 232-259.

Curran, J. (1993) TECs and Small Firms: Can TECs Reach The Small Firms Other Strategies Have Failed To Reach? Kingston University.

Curran, J. and Blackburn, R. (1994) Small firms and local economic networks: the death of the local economy? London: Paul Chapman.

Dawson, C., Henley, A. and Latreille, P. (2012) Individual Motives for Choosing Selfemployment in the UK: Does Region Matter? Regional Studies, 48, 5, 804-822. DOI: 10.1080/00343404.2012.697140

DECC (2011) Evaluation of the Community Energy Saving Programme. London: DECC. https://www.gov.uk/government/uploads/system/uploads/attachment_data/file/4 8210/3342-evaluation-of-the-community-energy-saving-programm.pdf]

Defra (2013) Green Infrastructure's Contribution to Economic Growth: a review. London: Defra.

Eadson, W. (2011) Sub-national interventions for carbon reductions in SMEs: a review of the evidence. Sheffield: Sheffield Hallam University. 
p. 138. Towards a spatially and socially embedded approach to SME support for carbon reduction

Enviros (2007) Managing a successful green business park (gbp) - lessons from the enworks programme. Manchester: Enviros. http://enworksinabox.com/evaluation

Farinelli, U., Johansson, T. B., McCormick, K., Mundaca, L., Oikonomou, V., Örtenvik, M., Patel, M. and Sinti, F. (2005) "White and Green": Comparison of market-based instruments to promote energy efficiency. Journal of Cleaner Production, 13, 10151026.

Federation for Small Business (2008) Social and Environmental Responsibility and the Small Business Owner. http://www.fsb.org.uk/policy/assets/CSR\%20Dec\% 202008.pdf

Foden, M. (forthcoming, 2015) Saving time, saving money, saving the planet, 'one gift at a time': a practice-centred exploration of free online reuse exchange. Ephemera, 15.

Fuller, T. and Lewis, J. (2002) 'Relationships Mean Everything'; A Typology of SmallBusiness Relationship Strategies in a Reflexive Context. British Journal of Management, 13, 4, 317-336.

Giddens, A. (1984) The Constitution of Society. Cambridge: Polity Press.

Hargreaves, T. (2011) Practice-ing behaviour change: Applying social practice theory to pro-environmental behaviour change. Journal of Consumer Culture, 11, 1, 79-99.

Higgins, D. and Mirza, M. (2012) Considering Practice: a contemporary theoretical position towards social learning in the Small Firm. The Irish Journal of Management, 31, 2.

Jonas, A.E.G. (2006) Pro scale: further reflections on the 'scale debate' in human geography. Transactions of the Institute of British Geographers, 31, 3, 399-406.

Lefebvre, H. (1974) La production de l'espace. Paris: Anthropos.

Levitt, T. (2013) The Social SME. York: Joseph Rowntree Foundation.

McKeever, E., Anderson, A. and Jack, S. (2014) Social embeddedness in entrepreneurship research: the importance of context and community. In: Chell, $E$ and Karatas-Ozkan, M Eds. (2014) Handbook of Research on Small Business and Entrepreneurship. London: Edward Elgar.

Mole, K.F., Hart, M., Roper, S. and Saal, D.S. (2009) Assessing the Effectiveness of Business Support Services in England: Evidence from a Theory-Based Evaluation. International Small Business Journal, 27, 557-579.

NatWest/SERTeam (2004) Quarterly Survey of Small Business in Britain. http://www.open.ac.uk/business-school/news/school-publications/quarterly-survey

$\begin{array}{lllll}\text { Netregs (2009) SM-Environment Survey 2009. Netregs. } & \text { S }\end{array}$ http://www.netregs.org.uk/pdf/NetRegs SME Environment 2009 UK summary.p df

Parker, C.M., Redmond, J. and Simpson, M. (2009) A review of interventions to encourage SMEs to make environmental improvements. Environment and Planning C, 27, 279-301.

Revell, A. and Rutherfoord, R. (2003) UK environmental policy and the small firm: broadening the focus. Business Strategy and the Environment, 12, 26-35.

Revell, A., Stoker, D. and Chen, H. (2009) Small Business and the Environment: turning over a new leaf? Business Strategy and Environment, 19, 5, 273-288.

Spence, L.J., Schmidpeter, R. and Habisch, A. (2003) Assessing Social Capital: Small and Medium Sized Enterprises in Germany and the U.K. Journal of Business Ethics, 47, 17-29.

Vaara, E. and Whittington, R. (2012) Stragety as practice: taking social practices seriously. The Academy of Management Annals, 6, 1, 285-336.

Vickers, I., Vaze, P., Corre, L., Kasparova, E. and Lyon, F. (2009) SMEs in a Low Carbon Economy. London: BERR.

Warren, L. (2004) Negotiating entrepreneurial identity: communities of practice and changing discourses. International Journal of Entrepreneurship and Innovation, 5, 1, 25-35. 